\title{
A phase of consolidation before moving forward again
}

It struck me recently that we have entered a consolidation phase in exercise science and sports medicine. The exponential increase in knowledge that we have experienced since the early 1980 s seems to have stabilised. This thought came about after the recent publication of excellent reviews on a variety of topics. A key point is that these publications have focused on the translation of the research, emphasising the practical guidelines. These articles have set the standard for best practice. Consider as an example the research on concussion. The recent consensus statement ${ }^{[1]}$ is written for healthcare professionals who deal with athletes, and provides tools that can be used to individualise the return-to-play decisions after an athlete is concussed. The document is exhaustive and provides a sports concussion assessment tool (SCAT3), including one designed for children. There is even a concussion recognition tool (CRT) designed for non-professionals. Armed with the information provided in this document, a healthcare professional can provide high-level management to an injured athlete, and be guided on the steps for safe return-to-play. The foundations have been laid for universal, good management; this information is in the public domain and is freely available. Future research on the management of concussed athletes will be guided by questions arising from the foundation that has been set in this consensus statement.

Another example of the consolidation of knowledge was published a few weeks ago. ${ }^{[2]}$ This occurred in the important area of managing players' wellbeing, in particular the management of their health, risk of injury and training status. This article was written by Paul Dijksra, ${ }^{[2]}$ a South African who studied medicine at the University of Pretoria and sports medicine at the University of Cape Town. He was the chief medical officer of UK Athletics and is currently working in Qatar as the assistant chief of sports medicine for the Qatar Sports Medicine Department. This article describes a framework designed for the continuous monitoring and management of the health and performance of athletes. The structured approach assists with decisionmaking about training and competing, especially while the athlete is ill or injured. The Integrated Performance Health Management and Coaching model considers the best medical advice and individualised needs of the athlete. As with the concussion consensus document, this article is rich in theoretical, supportive information, which is translated into systematic, clear guidelines for practitioners. Anyone entering the field can use this as a blueprint, comforted by the fact that they are providing a high level of service if they implement the guidelines.

Documents such as these may create the impression to a newcomer to the field of exercise science and sports medicine that all the questions have been answered. Nothing could be further from the truth. There is still much work to be done, and there are many more questions to answer. As our collective knowledge evolves, the questions subjected to research merely become more specific and focused, either in striving to understand the mechanisms of action, or in trying to determine the efficacy of the intervention. There will always be a need to offer services to athletes that reduce the risk of injury, ensure health and wellbeing, while increasing the chances of the athlete peaking at the right time. While the latest articles translating theory into practice show that we have made excellent progress in the last 30 years, there will always be questions that need to be answered to enable these services to be optimised and fine-tuned.

This edition of the journal, the first in 2014, showcases South African research on musculoskeletal injuries in female adolescent hockey players, ${ }^{[3]}$ collagen gene interactions and endurance running performance, ${ }^{[4]}$ and the feasibility of pedometer based-health promotion. ${ }^{[5]}$ There is also a study, ${ }^{[6]}$ submitted by researchers in the UK, in which goal expectations and performance in time trials between successful and unsuccessful cyclists were assessed. A reminder that

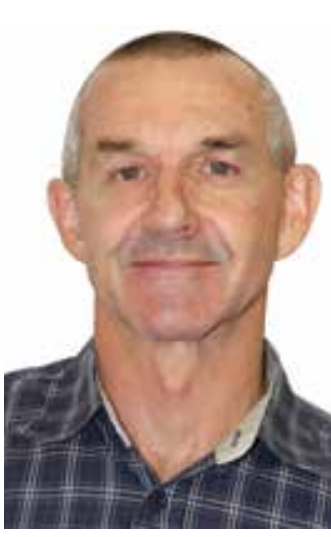
the South African Sports Medicine Association (SASMA) represents several disciplines and this journal, being the mouthpiece of SASMA, has to reflect this. Readers are encouraged to submit original research, case studies or commentaries. Guidelines for the format of the article submissions are available online at http://www.sajsm.org.za.

\section{Mike Lambert}

Editor-in-Chief

1. McCrory P, Meeuwisse WH, Aubry M, et al. Consensus statement on concussion in sport: The 4th International Conference on Concussion in Sport held in Zurich, November 2012. Br J Sports Med 2013;47(5):250-258.

2. Dijkstra HP, Pollock N, Chakraverty R, Alonso JM. Managing the health of the elite athlete: A new integrated performance health management and coaching model. $\mathrm{Br} \mathrm{J}$ Sports Med 2014;48(7):523-531.

3. Ellapen TJ, Bowyer K, van Heerden HJ. Common acute and chronic musculoskeletal injuries among female adolescent field hockey players in KwaZulu-Natal, South Africa. South African Journal of Sports Medicine 2014;26(1):4-8. [http://dx.doi. org/10.7196/SAJSM.482]

4. O'Connell K, Posthumus M, Collins M. Collagen gene interactions and endurance running performance. South African Journal of Sports Medicine 2014;26(1):9-14. [http://dx.doi.org/10.7196/SAJSM.523]

5. Pillay JD, Kolbe-Alexander TL, Proper KI, van Mechelen W, Lambert EV. Steps that count! A feasibility study of a pedometer-based, health-promotion intervention in an employed, South African population. South African Journal of Sports Medicine 2014;26(1):15-19. [http://dx.doi.org/10.7196/SAJSM.500]

6. Rhoden C, West J, Renfree A, Corbett M, St Clair Gibson A. Micro-oscillations in positive and negative affect during competitive laboratory cycle time trials - a preliminary study. South African Journal of Sports Medicine 2014;26(1):20-25. [http://dx.doi.org/10.7196/SAJSM.496]

S Afr J SM 2014;26(1):3. DOI:10.7196/SAJSM.538 